\title{
Advanced nursing practice: strategies for training and knowledge building
}

\author{
Maria Lúcia Zanetti
}

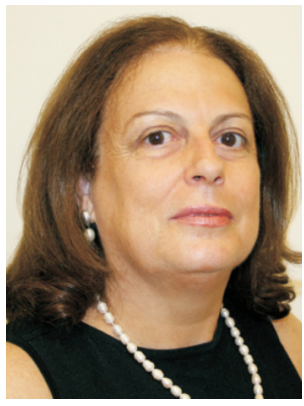

We currently live in an era of uncertainty, characterized by profound changes and a complex resizing economic, social, political, cultural and environmental, that affects society in general and particularly people's lives. These changes also affect the areas of knowledge, broadening the communication mechanisms due to technological advances and use of sociocultural networks that have dramatically changed the understanding of the contemporary world. This setting creates new challenges, searching for innovations and ways of thinking and grasp. In regard to, it is important to guarantee the training of highly qualified human resources and the construction of knowledge through a democratic process work, committed to ethical, humanist and egalitarian values in a supportive and constructive organizational environment. This based on partnerships and collaboration internal and external. These requirements are essential to achieve the millennium development goals for health education.

This way seeking to overcome the challenges of qualification of human resources in health, the Pan American Health Organization, while editing the resolution "Human Resources for Health: expanding access to qualified health professionals in health systems based on primary health ", they highlights the importance of the performance of advanced practice nurses, anchoring health systems based on Primary Health Care in Latin America(1). Although many countries are committed to the training of nurses for advanced practice nursing, it is necessary to expand training strategies of nurses with expertise in the areas of critical content.

To understand this global trend we highlight the concept of the International Council of Nurses (ICN) for advanced nursing practice: "Advanced Nursing Practice requires nurses to include in their training; expertise, skills and expertise to the decision-making in complex situations in various scenarios of practice"(2). Nurses need to deepen their knowledge in; family health care, to the individual adult care, primary care, women in labor, specialized clinics, anesthesia, community health, women's health, emergency, pediatrics, gerontology and the people in need of acute care. Nursing education involves their preparation for education at an advanced level, formal recognition of educational programs, offering courses with objectives and content aimed at the advanced practice and the accreditation by competent $\operatorname{organs}^{(3)}$.

Thus, strategies must be adopted by educational institutions, among which stand out: broaden approach of the content with critical areas such as; advanced practice in public health, advanced nursing in social and behavioral science focused on population, theoretical models of nursing, interdisciplinary team, leadership, systematic thinking, biostatistics, epidemiology, environmental health, health policy and management, health informatics, genomics, health communication, cultural competence, global health, politics and law and ethics in public health. It is emphasized that nursing education should include knowledge based on robust evidence in nursing and health. As well as skills and expertise to establish and lead interdisciplinary teams, enabling creative solutions, effective and low cost to the population. It is expected that nurses when acquiring competence in the areas of critical content, can meet the challenges of emerging health, as the rapid change of social structures, the need for production and rapid availability of knowledge applied to the health of the population and new health technologies ${ }^{(3)}$.

How can nurses benefit from the advanced practice nursing strategies in their professional practice? There are numerous situations that could be listed in order to show how this settlement of advanced practice resources into concrete strategies occurs. A few of them will be highlighted. When nurses, when implementing a prevention program 
of foot ulcers in diabetes mellitus patients, show improvement in some health indicators, such as; reducing the number of amputations, hospitalizations and health costs. Or when assuming their share of responsibility in monitoring pregnant women with a view to normal childbirth, nurses are able to show how advanced practice can reduce the number of unnecessary cesareans. Still, when prescribing medicines for patients with chronic diseases, the follow-up shows a good control of the disease. Or when dedicated to the development and validation of models on social and behavioral science to strengthen patients' adherence to healthy behaviors, reducing the number of patients to health services, among other possible strategies.

In Brazil the 14 graduate courses with eye on the master's degree, could enable the advanced nursing practice to consider their vocation in search strategies for the qualification of human resources for solving the population's health problems. These courses, the contribution with innovative proposals to solve the professional nursing practice issues, generating products and technologies for the best performance in the development of nursing and health, are in line with the definition and characteristics of advanced nursing practice ${ }^{(4)}$.

The teacher training is also a challenge to be highlighted because it is necessary that teachers incorporate this trend. Among other demands there are; a shortage of qualified human resources in health, a complexity inherent to health services, lack of evidence in the nursing literature to support this practice, lack of recognition of nurse specialist by the population, impaired performance in complex health systems and dividing work, participating in an interdisciplinary team, in addition to the notorious shortage of innovative approaches in nursing curricula.

There is also the urgent need for review of incentive policies and lines of financing for development agencies to research, in order to stimulate the production of knowledge in advanced nursing practice. The production of knowledge in advanced nursing practice could help to remedy the gap in terms of innovative knowledge and focus on population problems. Thus, it can make way for the construction of a science in nursing, committed to the reality of the population that will affect the recognition of nurses by the company as an agent for the quality and safety of care.

Within this framework, we encourage nursing researchers to submit original articles on advanced nursing practice for the RLAE.

\section{References}

1. World Health Organization. Global status report on noncommunicable diseases. Geneva: WHO; 2010.

2. Organização Mundial da Saúde. Cuidados inovadores para as condições crônicas: componentes estruturais de ação: Relatório Mundial. Brasília; 2013.

3. Organización Panamericana de la Salud. Cuidados innovadores para las condiciones crónicas: Organización y prestación de atención de alta calidad a las enfermedades crónicas no transmisibles en las Américas. Washington, DC: OPS; 2013.

4. Janine RR. O mestrado profissional na política atual da Capes. RBPG. 2005;2(4):8-15.

Maria Lúcia Zanetti is Associate Editor of the Revista Latino-Americana de Enfermagem, and Associate Professor of the Escola de Enfermagem de Ribeirão Preto, Universidade de São Paulo, PAHO/WHO Collaborating Centre for Nursing Research Development, Brazil, e-mail: zanetti@eerp.usp.br. 